\title{
Ocean acidification promotes cellular burst on photosynthetic (kleptoplastic) sea slugs
}

Dionísio, G. ${ }^{*, * *}$, Cruz, S. ${ }^{* *}$, Serôdio, J. ${ }^{* *}$, Calado, R. ${ }^{* *}$, Rosa, R. ${ }^{*}$

*Laboratório Marítimo da Guia, Centro de Oceanografia, Faculdade de Ciências da Universidade de Lisboa, Av. Nossa Senhora do Cabo, 939, 2750-374 Cascais, PORTUGAL.

** Departamento de Biologia \& CESAM, Universidade de Aveiro, Campus Universitário de Santiago, 3810193 Aveiro, PORTUGAL.

Email: gisela.dionisio@ua.pt

Ocean acidification is known to trigger deleterious effects on several marine photosynthetic invertebrates [1]. Photosymbiosis, whereby photosynthetic microorganisms or organelles live inside an animal (host) is widespread in the marine biota, underlying a wide range of ecologically and biogeochemically significant processes that remain largely unclear [1]. One of the most remarkable symbiosis is between sacoglossan molluscs and algal chloroplasts [2]. These organisms are able to "steal" functional chloroplasts (termed kleptoplasts) from their algal prey and keep them functional inside digestive diverticula [2]. The aim of this study was to investigate the impact of environmental hypercapnia on cellular structures of kleptoplastic animals. Elysia viridis (Sacoglossa) were exposed to different $\mathrm{pH}$ conditions (pH 8, 7.5, 6.8 and 6.1) for 24 h. Six animals were anaesthetized per treatment [3] and the integrity of kleptoplasts was determined (in vivo) under optical and stereomicroscope (Figs. 1,2). Morphological modifications to the normal condition of digestive diverticula, chloroplasts and mortality, were checked every $8 \mathrm{~h}$ Under normal conditions ( $\mathrm{pH}$ 8.0) the symbiotic chloroplasts are packed tightly in the tubule cells, particularly close to cell walls (Fig. 2A, arrow). Tubule cells ramify throughout the body, giving its green appearance. The same condition was verified for $\mathrm{pH} 7.5$ (Fig. 2B). Sea slugs subjected to $\mathrm{pH} 6.8$ presented fragmented clusters of chloroplasts and overall color variation (Figs. 1, 2C). Mortality was only verified in animals exposed to pH 6.1 (100\% mortality), presenting severe impacts at cellular level after $24 \mathrm{~h}$ of exposure, including cellular burst (Fig. 1). Chloroplasts and their plastoglobuli spread across host cytoplasm (Fig. 2D, arrow) and cellular layers surrounding the plastid were absent. These preliminary results suggest that E. viridis may resist to environmental hypercapnia down to $\mathrm{pH}$ 6.8, where the first sings of cellular modifications where detected. At pH 7.5 (future scenario, 2100 [4]) kleptoplastic sea slugs retain their endosymbionts in opposition to other well-established photosymbiotic groups.

Gisela Dionísio acknowledge Portuguese Science Foundation (FCT) for the $\mathrm{PhD}$ grant SFRH/BD/73205/2010. This work was supported by European Funds through COMPETE and by National Funds through the FCT within project PEst-C/MAR/LA0017/2013.

1. Dupont, S. et al.; PloS one, 7, e29568, 2012.

2. Rumpho, M. E. et al.; The Journal of Experimental Biology 214, 303-311, 2011.

3. Cruz, S. et al.; The Biological Bulletin 223, 328-336, 2012.

4. Caldeira, K. and Wickett, M. E.; Journal of Geophysical Reasearch, 110, 2005. 


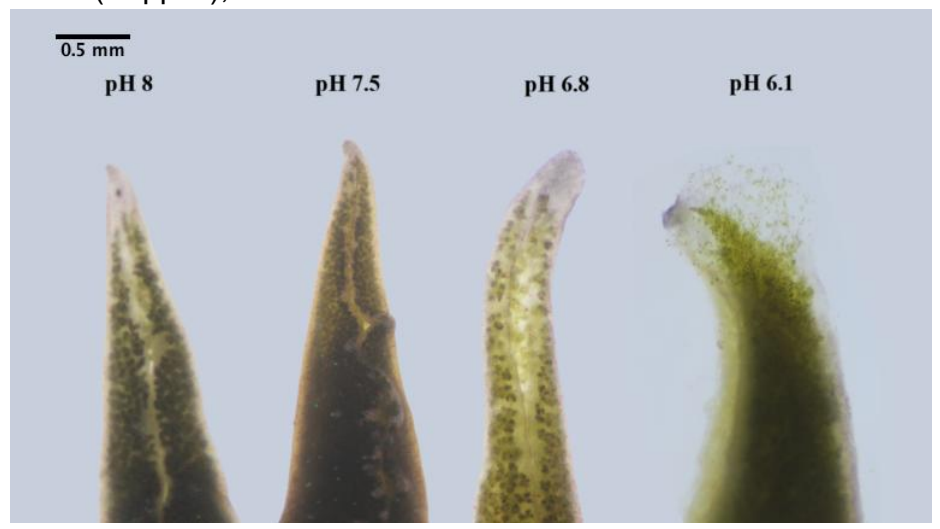

Fig. 1 - Posterior sections of $E$. viridis exposed to different $\mathrm{pH}$ conditions for $24 \mathrm{~h}(8,7.5,6.8$ and 6.1$)$ observed under optical stereomicroscope; green coloration is given by chloroplasts and evident burst is shown under $\mathrm{pH}$ 6.1. Scale bar: $0.5 \mathrm{~mm}$.

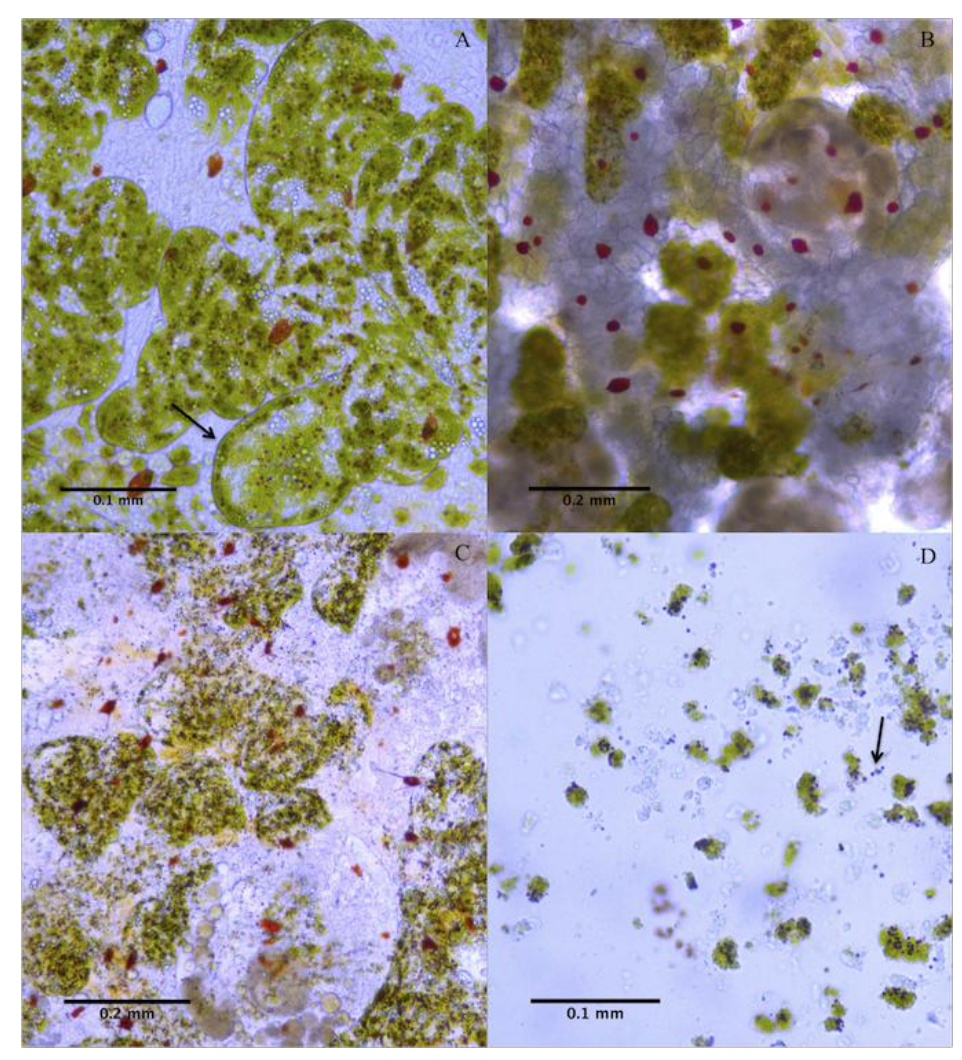

Fig. 2 - Digestive diverticula from posterior sections of $E$. viridis exposed to different $\mathrm{pH}$ conditions for $24 \mathrm{~h}(\mathrm{~A}-\mathrm{pH} 8 ; \mathrm{B}-\mathrm{pH} 7.5 ; \mathrm{C}-\mathrm{pH} 6.8 ; \mathrm{D}-\mathrm{pH} 6.1)$, observed in vivo under optical microscopy. Normal $\mathrm{pH}$ conditions (A) show numerous algal plastids within a cell (black arrow, A), contrasting with the absence of cellular layers surrounding the plastids, and plastoglubuli (black arrow) spread across host cytoplasm at the lowest $\mathrm{pH}(\mathrm{D})$. Scale bars: $0.1 \mathrm{~mm}(\mathrm{~A}, \mathrm{C})$ and $0.2 \mathrm{~mm}(\mathrm{~B}, \mathrm{D})$. 